\title{
Accessibility, affordability and equity: assessing 'pro-poor' public transport subsidies in Bogotá
}

\author{
Luis A. Guzman \\ Grupo de Sostenibilidad Urbana y Regional, SUR \\ Departamento de Ingeniería Civil y Ambiental, Universidad de los Andes \\ Edificio Mario Laserna Cra $1^{\circ}$ Este N 19a-40 Bogotá, Colombia: Tel (+571)3394949 \\ la.guzman@uniandes.edu.co \\ Daniel Oviedo \\ Development Planning Unit \\ University College London \\ Gower St, London, WC1E 6BT \\ d.oviedo.11@ucl.ac.uk
}

\begin{abstract}
Public transport has claimed a preferential position in recent urban development agendas internationally. Rising interest on inclusive development of cities at different levels of urban policy involves new opportunities and challenges for increasingly urban societies. In cities of the Global South, in addition to institutional and physical challenges for the development of efficient and inclusive public transport, local governments face the challenge of making public transport affordable for a large share of the population in conditions of poverty. In order to meet these challenges, several public transport systems throughout have implemented targeted subsidies for specific social groups such as students, the elderly and people with reduced mobility, and more recently for the poor. The government of Bogotá has implemented a pro-poor public transport subsidy scheme that aims at alleviating the financial burden of poor households for accessing the city's public transport system. This research develops an analysis of the effects of such subsidy from an accessibility perspective using potential accessibility measures to employment opportunities and assess its impact on equity. The research builds on the hypothesis that accessibility is a multidimensional construct that can benefit from the decrease in economic as much as gains in time costs. Results from the analysis show that both the current structure of the pro-poor subsidies in Bogotá and alternative scenarios for increasing its coverage are progressive, improving accessibility and equity for those with access to the subsidy. The paper provides valuable insights for the analysis of similar policies in other urban contexts in the Global South.
\end{abstract}

Keywords: public transport; transport subsidies; job-accessibility; equity; Palma ratio, Gini index, Bogotá 


\title{
Accessibility, affordability and equity: assessing 'pro-poor' public transport subsidies in Bogotá
}

\begin{abstract}
Public transport has claimed a preferential position in recent urban development agendas internationally. Rising interest on inclusive development of cities at different levels of urban policy involves new opportunities and challenges for increasingly urban societies. In cities of the Global South, in addition to institutional and physical challenges for the development of efficient and inclusive public transport, local governments face the challenge of making public transport affordable for a large share of the population in conditions of poverty. In order to meet these challenges, several public transport systems throughout have implemented targeted subsidies for specific social groups such as students, the elderly and people with reduced mobility, and more recently for the poor. The government of Bogotá has implemented a pro-poor public transport subsidy scheme that aims at alleviating the financial burden of poor households for accessing the city's public transport system. This research develops an analysis of the effects of such subsidy from an accessibility perspective using potential accessibility measures to employment opportunities and assess its impact on equity. The research builds on the hypothesis that accessibility is a multidimensional construct that can benefit from the decrease in economic as much as gains in time costs. Results from the analysis show that both the current structure of the pro-poor subsidies in Bogotá and alternative scenarios for increasing its coverage are progressive, improving accessibility and equity for those with access to the subsidy. The paper provides valuable insights for the analysis of similar policies in other urban contexts in the Global South.
\end{abstract}

Keywords: public transport; transport subsidies; job-accessibility; equity; Palma ratio, Gini index, Bogotá 


\section{Introduction}

Transport costs can represent a heavy burden for household expenditures, particularly in low-income households. The poor invest an important part of their income on their commutes, which restricts disposable income for other travel purposes and activities. Lack of transport can translate into difficulties for access to social life, education and health facilities and economic opportunities (Willoughby 2002). Low-income workers have a pressing need for adequate and affordable transport services (El-Geneidy, Legrain \& Buliung 2016). In developing contexts, low-income groups have a narrow absolute limit to the number of journeys possible by low and often erratic monetary incomes, which in turn limits their chances of becoming less poor. Therefore, the development an improved understanding of these travel behaviours (Lucas et al. 2016) and their impacts on access to opportunities should become a priority in current research and policy agendas.

In Latin America, urban poverty and 'peripherality' often come hand in hand, which restricts further accessibility by adding a spatial dimension to already limited travel choices due to low purchasing power (Dávila et al. 2006, Gilbert, Ward 1982). Ureta (2008), finds that peripheral location limits people's ability to travel by foot, at the same time as high costs of public transport in relation to household income restricts people's movement to the strictly essential (work and education). As employment is the main source of income that facilitates other activities (Loo, Chow 2011), governments have the responsibility to improve access to jobs for the most disadvantaged. This is linked with design of transport policies aiming at closing the access gap between residents. Although the goal of increased access to economic opportunities can be instrumental in reducing poverty and improving quality of life, available mechanisms for doing so are often impaired by financial constraints both in the demand and supply side of urban transport.

Public transport plays a central role in the accessibility levels of urban populations. In cities with low car-ownership rates, public transport becomes the main mechanism to articulate urban structures and provide access to the territory within goals of sustainability. In Bogotá and Soacha (the most populous neighbouring municipality), public transport supplies the largest share of the demand of low-income populations, excluding walking and cycling. Unfortunately, one of the main characteristics of Bogotá's transport structure -and that of cities with similar public transport systems- is that fares for public transport services are designed to cover the entirety of operating costs (Hidalgo, Gutierrez 2013). As it is nearly impossible to make fares both affordable and financially sustainable, transport fares tend to become too expensive for the city's poor (Rodriguez et al. 2016). To balance the needs for economic and social sustainability, some cities have tried to implement targeted transport subsidies for specific segments of the population. However, these policies are yet to gain sufficient traction at the international and national levels to become a mainstream response to widespread affordability concerns for low-income communities throughout cities of the Global South.

In Bogotá, the implementation of the Integrated Public Transport System (SITP in Spanish) has incorporated not only an integrated fare for the operation of all its public transport subsystems, like Transmilenio (TM, local BRT system) and traditional buses. The SITP is a large-scale initiative by which the city's nearly 700 bus routes and more than 15,000 traditional urban buses are being transformed into a regulated, publicly tendered system with high level of service. The SITP aims to eliminate the inefficiencies of the traditional bus system by introducing $p p p$ contracts that restructure bus routes, regulate oversupply and change contractual arrangements and incentives with operators to eliminate the infamous 
penny war that characterized the traditional bus system (Ardila 2005). In 2014, the local government introduced a pro-poor public transport subsidy that builds upon a social policy targeting mechanism developed by the national government called SISBEN to allocate public transport subsidies that allow discounted access to lower income households to the SITP.

Our research places itself in recent debates around the links between affordability, accessibility and transport equity, documenting the targeted subsidies as an example of implementation of a transport policy with a social focus in a well-known case of urban transport development in Latin America such as Bogotá. The paper seeks to highlight the contribution of targeted policies aiming to improve affordability of socially vulnerable populations to accessibility using consolidated accessibility metrics and easily understandable and readily available information in most cities of the Global South. While transport evaluation continues to hold a primary place in current transport policy and planning, equity assessments are less than frequent and imply increasingly complex understandings of the role of transport on issues such as accessibility, mobility, and health wellbeing (Oviedo, Dávila \& Levy 2017, Di Ciommo, Shiftan 2017). The paper is supported by relatively simple, accessible and intelligible information for both specialist and nonspecialist audiences in practice and decision-making. The paper reflects on the moral concern of equity, described as the need to reduce systematic discrimination and marginalisation, and sometimes understood as the absence of systemic inequalities between different social groups (Wiles, Kobayashi 2009). In this regard, the paper proposes the understanding of accessible opportunities as an unequally distributed outcome of the configuration of the land-use and transport systems in Bogotá. By recognising that transport can play a differentiating role in enabling a redistribution of accessibility (Lucas et al. 2016), we argue that broader discussions are necessary to introduce equity considerations and the complex effects of transport on human development.

We explore the effects on accessibility to income-generating opportunities and affordability of the implementation of a targeted public transport subsidy for low-income populations in the city of Bogotá. Despite the long history of accessibility metrics in the international literature and practice in many cities of the Global North, traditional approaches to public transport policy evaluation in most cities in the Global South do not consider accessibility changes. This research focuses on potential accessibility calculations for Bogotá and Soacha. We analysed the development of potential accessibility to employment for the 20112015 period, because of the implementation of the SITP and its fare subsidies, keeping landuse changes constant. This is based on the calculation of potential accessibility levels to the labour market per zone for Bogotá and Soacha, by introducing a function of impedance composed by travel time and monetary costs.

The article does not attempt to suggest new methodological approaches to the analysis of accessibility or the assessment of transport subsidies or similar policies. However, we suggest that the use of equity measures, often applied only to income distribution at zonal level, may be applied to accessible opportunities, understanding these as an inequitably distributed asset. In turn, the paper seeks to showcase how can targeted policies be justified from an equity perspective using well-known methodologies and easily understandable information. Our work seeks to add elements to the debates at the national and international levels in relation to the understudied benefits of pro-poor public transport subsidies, and how can readily available evidence be used to bridge the gaps between technical and nontechnical criteria. The research therefore responds to two overarching hypotheses: (i) that pro-poor public transport subsidies can reduce the accessibility gaps between better-off and lower income population; and (ii) that accessibility and equity metrics are an effective form 
of evidence for supporting moral arguments related to the reduction of inequalities through transport policy.

\section{Location of activities and transport in Bogotá}

Bogotá is a city of 7.8 million people and an urbanized area of approximately $414 \mathrm{~km}^{2}$ in 2015. It currently forms a conurbation with 17 of the surrounding municipalities, amongst which the most important is Soacha with about 511,000 inhabitants (Guzman, Oviedo \& Bocarejo 2017). The latter is forms a complex functional area with Bogotá, which has been gradually emerging as the cities extend beyond their administrative boundaries (Oviedo, Dávila 2016). For this analysis purpose, Bogotá is divided into 112 urban "zonal planning units" (UPZ), which are territorial units used to plan urban development at the zonal level and follow recognizable boundaries such as roads and natural barriers. Soacha is divided into four different zones.

The study area (Bogotá and Soacha) has some particularities in terms of spatial distribution of activities (residing and work). Figure 1 shows the spatial distribution of population (left) and employment density (right). The employment data includes both formal and informal workplaces. Because of an historic housing deficit, many informal neighbourhoods emerged on the city's peripheries characterized by poor urban living conditions, which have been formalized over time. It is in these border zones where the highest population densities occur.

Figure 1. Population and employment location Source: Own elaboration based on Mobility Survey 2011

Figure 1 shows very high population densities in urban peripheries where there is a deficit of local employment in comparison with the resident population. Regarding location of jobs, there is a clear dominance of a large concentration of employment in an extended centre along major road corridors in the northern and eastern sides of the city (the wealthier zones). Just over one-third of the city's employment occurs in zones occupying only $10 \%$ of its urban land area. The evidence in Figure 1 suggests a particularly stark reality: people do not live where the jobs are. The 2011 mobility survey ${ }^{1}$ reports the monthly income of each household in $\mathrm{USD}^{2}$ within eight predefined ranges as shown below:

\section{Table 1. Average income per household in USD}

The spatial distribution of households in Bogotá and Soacha under the above income classification is shown in Figure 2. The evidence shows $66 \%$ of the households in Bogotá belong to the lowest income ranges (1 and 2), while in Soacha this proportion is $86 \%$. As shown in Figure 2, economic segregation is widespread in the city, with lower income zones located in the urban periphery (mainly in the south and south-west, as well as some at the northern edges of the city), whereas the richest areas are north of the traditional city centre.

\footnotetext{
${ }^{1}$ It was not possible to use the last mobility survey (2015), because it statistical representativeness is not enough for the spatial disaggregation of this study.

${ }^{2}$ Colombian Peso in 2011: 1 USD $=1,900$ COP.
} 
Figure 2. Public transport system characteristics and income per household Source: Own elaboration based on Mobility Survey 2011

The effects of such a spatial mismatch include high travel times in public transport, in some cases reaching more than one and a half hours per trip. The spatial distribution of economic opportunities and socio-demographic groups has direct implications both in the travel costs and the travel capacity of households in the poorest segment of the population (Guzman, Oviedo \& Rivera 2017). Our diagnosis shows that commuting trips by public transport are around 0.55 trips per day in low-income households (ranges 1 and 2), while trips by private car and non-motorized modes are 0.16 and 0.23 respectively. Despite this low trip generation, the average percentage of individual monthly income spent on transport in this particular group could be exceeds $27 \%$ (Rodriguez et al. 2016).

The public transport system has coverage in almost the entire city with a vehicle fleet of 2,027 buses in the BRT system and 6,769 buses in the zonal component of SITP in 2015. Public transport (TM and regular buses) supplies around $60 \% \%$ of all motorized trips in the city. However, non-motorized trips are more frequent in low-income groups: for work purposes, this segment of the population uses public transport $(58 \%)$ and walk and cycling $(24 \%)$. Although system coverage is acceptable, route frequencies are very low mainly in some peripheral zones, providing a low level of service. The SITP has three components. The first is the zonal service which is provided by regular public buses in mixed traffic that replaced the traditional bus services. The cost for zonal services was 1,550 Colombian Pesos $\left(\mathrm{COP}^{3}\right)$ in 2015. The second component are feeder buses that connect peripheral zones with the trunk lines of the TM system. Feeders have no additional fare for their use. TM's fare was 1,800 COP in 2015. All these modes of transport are fully integrated though a fare collection system based on smart cards currently are under use in the city and operated by a private operator called Recaudo Bogotá. By 2015 (December), the implementation of the SITP and corresponding phasing out of the traditional system was at almost $72 \%$, which meant a relatively large coverage of public transport in the city.

However, fare integration does not necessarily imply better accessibility (Bocarejo et al. 2016): the reorganization of routes, including new requirements for transfers, may result in an increase in travel times and costs in certain zones. These route changes could be potential barriers to accessibility levels, particularly in more peripheral areas. Although both the SITP and the pro-poor subsidy, represent an effort from previous administrations in Bogotá to improve accessibility for the majority of the population who depend on public transport. The targeted subsidy is the first public transport policy in the city that addresses explicitly affordability barriers for low-income populations, one of the main constraints for accessibility in this segment of the demand (see Bocarejo and Oviedo, 2012; Guzman et al., 2017).

Households with lower income spend large amounts of time and a significant part of their daily income traveling (Bocarejo et al. 2016) as shown in Figure 2 (poorest zones have higher travel times). The current structure of the public transport system therefore can entail negative impacts in relation to the quality of life of low-income people who find themselves forced to withstand large expenditure, discomfort and less time for other activities due to lack of adequate alternatives for their travel. Although the introduction of TM revolutionized high-capacity public transport in the city, travel times remain high for low-income

3 Colombian Peso in 2015: 1 USD $=2,775$ COP. 
households, almost twice the travel times higher-income population (Guzman, Bocarejo 2017).

These conditions are worsened by concentration of income-generating activities in a central core at the centre of Bogotá (darker zones, Figure 1 right), which is also where higher income people live. This makes people living closer to the urban peripheries experience extremely unequal conditions in terms of mobility patterns. Arguably, Bogotá suffers from a spatial mismatch that has negative effects on accessibility as lower-income households locate mainly on the south and west edges of the city, away from the areas with a higher density of work opportunities (Guzman, Oviedo \& Rivera 2017).

\subsection{Characterization of households}

Available evidence suggests that as a household's income increases, its mobility grows (Guzman, Gomez \& Rivera 2017). Daily trip rates for low-income people, is 2.16 trips per day, while for a household belonging to income range 8 , the same rate is $23 \%$ higher. These differences in trip rates are more evident when the analysis is limited to work trips: a wealthy household makes $110 \%$ more trips to work than a low-income person (see Table 2).

Additionally, there are important differences in the use of transport modes. Table 2 show that low-income workers use public transport more than their wealthy counterparts for their commutes. Data suggests low-income households are very sensible to transport conditions, which could become explanatory factors in their mobility being reduced mainly to work trips due to both time and cost constraints. This will be further explored later in the paper.

Table 2. Main household's characteristics by income level

Differences between low-income households (ranges 1 and 2) and wealthier households (ranges 3 to 8 ) are striking as average gaps between socio-economic groups are around one trip per day even though household sizes are similar across the city. These initial findings may indicate that even if public transport is readily available (coverage and frequencies), it may not help poor workers get to where the jobs are in an efficient way.

Work destinations zones are shown in Figure 3 categorized in two groups: households in income ranges 1 and 2 and the rest. It is clear that work trips are concentrated in the east area of the city, where the most commercial, state-related and service activities are located. This area attracts about $30 \%$ of work trips. However, some differences are noticed between income groups: although a large share of work destinations of low-income households are concentrated in the expanded centre $(28 \%)$, the remaining two thirds of these trips are scattered practically throughout the entire city, with an important destination in Soacha. By contrast, travel patterns of the rest of the households show the expanded centre as the dominant destination. The former can be partially explained by a large concentration of lowwage and seasonal employment such as street vending, construction, security, and home cleaning among others, in the west-north and south borders of the city.

Figure 3 . Work destinations according income ranges

Source: Own elaboration based on Mobility Survey 2011 


\subsection{The targeted subsidies in the SITP}

In 1994, the Colombian government implemented a national scoring scheme known as Sistema Nacional de Beneficiarios (SISBEN) to categorize potential beneficiaries for social programs targeting population in conditions of poverty and social vulnerability. The SISBEN takes into consideration socioeconomic characteristics of the individuals and the household such as education, employment, income, housing characteristics, and household composition, among others, to assign a score between 0 and 100 categorized in six levels that can be used as a proxy to levels of poverty. The first two of such levels, which are defined below a score of 40 points, have incomes below Colombia's economic poverty line (monthly COP 229,672 in 2014). Bogotá's public transport subsidy was offered to citizens with a SISBEN score below 40 points. In Soacha, there are not subsidies as a result of legal and political constraints for Bogotá to invest in a different municipality. According to the SISBEN database, in April 2016 there are 2,403,674 people belonging to these two levels in Bogotá and 188,308 in Soacha. This highlights the large number of people who could access the transport subsidy.

The policy of subsidies was created under the agreement 603 of 2013, which was the landuse regulation plan for the former mayor Gustavo Petro between 2012 and 2016. This policy had its history in the city council of Bogotá in which it was submitted 14 times between 2008 and 2013. The main reason why this policy was criticized, and even demonized, in the city council was due to the lack of financial sustainability of the policy. However, the program was implemented in 2014 as a pro-poor transport policy aiming at improving affordability of the transit system for socially vulnerable populations. Subsequently some elements were modified by agreement 046 of 2016 . The policy was supported by a series of studies that showcasing how the poorest zones in Bogotá (several surveys) spent between $16 \%$ and $27 \%$ of their monthly income in commuting (Rodriguez et al. 2016).

In 2015, the subsidy corresponds to a discount of 900 COP covering 40 trips per month (or two trips per day during 20 business days). This subsidy scheme represents a $50 \%$ discount in TM services and a $60 \%$ discount in the zonal components per trip, although transfers between components of the SITP are not subsidized. Zonal-trunk and zonal-zonal transfers cost 300 COP within a 75 minutes window. The subsidy was delivered through a special smart card offered only to the potential beneficiaries of the policy. Those who were eligible had to request the subsidy.

Regarding the number of trips done by the totality of the subsidized smart cards, the majority of the subsidized trips were done in the south and south-western part of Bogotá, because there are the most of low-income residents. Since Soacha is another municipality, there are not transport subsidies for its inhabitants. Nevertheless, it is interesting how by normalizing the number of subsidized trips per population zone, the results present a similar pattern of usage the subsidies (see Figure 4).

Figure 4. Intensity of use of the transport subsidy (Jan-Nov 2014) Source: Own elaboration.

\section{Public transport accessibility analysis}

Cities in the Global South face high levels of inequality in relation to accessibility to opportunities and affordability to transport. Location-based accessibility measures have 
been used as an indicator that reflects availability of economic opportunities for different population groups (van Wee 2016). This research calculates public transport accessibility changes between 2011 and 2015 in Bogotá and Soacha, and determines whether targeted subsidies had an influence on accessibility levels of low-income population.

\subsection{Potential accessibility}

Potential accessibility metrics have been extensively covered in the international literature within transport studies and have been around since the mid-1950s. In the Global South, however, accessibility measures have only begun to appear in formal studies and evaluations after the turn of the new millennium. In this study, potential accessibility is defined with respect to job centres (Figure 1) and specifically includes a gravity model of interaction between job locations and commuting-trip origin zones. This type of model includes an attracting force (jobs) and the friction of intervening space measured as generalized travel cost. The accessibility of a zone in a (public) transport system is proportional to the spatial interaction between the origin trip zone and all other zones through a generalized travel cost decay function (Geurs, van Wee 2004).

The proposed model includes the combined effect of transport and land-use elements, and also incorporates assumptions on travel cost of transport by using an exponential decay function (Geurs, van Wee 2004). This gravity-based definition of accessibility (Wilson 2010, Hansen 1959) does not suffer from a strong dependence on the delimitation of the area of research because the addition of an irrelevant destination zone does not affect the accessibility values of the other zones (Bruinsma, Rietveld 1998).

This model includes an attraction factor and a separation factor. The potential accessibility model use generalized travel cost functions as a continuous measure that is then used to discount job opportunities with increasing time or distance from the origin zone. Then this accessibility model estimates the accessibility of job opportunities in zone $i$ to all other zones $(n)$ in which fewer and/or more distant workplaces provide less influence. The general metric used has been previously applied in Bogotá (Guzman, Oviedo \& Rivera 2017, Bocarejo, Oviedo 2012) and it is shown in equation (1):

$$
A_{i}=\sum_{j=1}^{n} O_{j} \cdot \exp \left(-\beta_{i} \cdot C_{i j}\right)
$$

Where $A_{i}$ is the accessibility in the zone $i$ to all job opportunities $O$ in zone $j, C_{i j}$ represents the generalized cost of travel function between zones $i$ and $j$, and $\beta_{i}$ are the calibration parameters from the gravity model (the cost sensitivity parameter) and have a significant influence on the accessibility levels. These parameters were empirically obtained from data of average spatial travel behaviour by zone, using the ordinary least squares method and the observed distributions of the generalized travel costs functions.

The obtained $\beta_{i}$ estimators are unbiased and efficient and shows $95 \%$ reliability, are different from zero, except four zones. From this, three zones are located in the urban fringe, with low population and generated trips. The last one corresponds to a metropolitan park. In this case, these zones are assigned a parameter of neighbouring zones with similar socioeconomic and mobility characteristics.

The generalized travel cost represents an impedance indicator, in monetary and temporary terms, of reaching job-related activities between an origin and a destination. Equation (2) presents the expanded formulation of the travel cost function: 


$$
C_{i j}=t_{i j}+{ }^{c_{i j}} / \text { VOT }
$$

The first component of the generalized travel cost, $t_{i j}$ is the travel time in public transport (either regular bus or TM) between $i$ and $j$, while $c_{i j}$ is the monetary expenditure of travelling (includes fares and transfers). Finally, VOT is the value of time in Bogotá for commuting trips, which was estimated by the authors in 69.6 COP/min in 2011.

The monetary component is closely associated with travel budgets, often limited to a given percentage of household income. Thus, the monetary cost of public transport system in Bogotá and Soacha determines if users are able, or not, to afford its use. In order to test our methodology, we decided to analyse potential accessibility in different zones of Bogotá and Soacha.

This measure represents accessibility at a zone in relation to all other zones. This approach allows to calculate the "range of choice" offered by the transport and land-use system in the form of a sum of potential job destinations (Koenig 1980). The higher this indicator, the more attractive the destination or lower the travel cost, or both. Such results are compared with the situation after SITP was implemented. However, this indicator does not account for the characteristics of the residents: all individuals in the same zone have the same level of accessibility.

\subsection{Affordability}

The main target of the subsidy is to make public transport more affordable for users within the lowest income ranges in the city. In Latin America, affordability is a big obstacle for the low-income population to have decent levels of accessibility (Hernandez, Falavigna 2016). Zones with higher transport costs are often more likely to experience social exclusion because of restricted accessibility and lack of mobility options that could result in lower economic activity (Saberi et al. 2017). With this analysis we want to complement the accessibility analysis and get a more complete picture of the effect of transport subsidies on the poorest population of the city.

In relation to social welfare, and in particularly to access to work, this can represent an important cost in travel expenditure as a function of the household income. According to a definition of affordability by Armstrong and Thiriez (1987), we estimate the observed affordability indexes for trips in public transport using what was declared on the survey day (expenditures and trips) and we expanded it to a month. This aggregated cost is then divided for the estimated average household income per zone (Figure 2), which gives a first indication of differences in public transport expenditure in the scenarios evaluated (see equation 3 ).

$$
A f f_{i}=\frac{k \cdot T_{i} \cdot E x_{i}}{Y_{i}}
$$

Where the observed public transport affordability index of zone $i\left(A f f_{i}\right)$ depend on the average household expenditure per trip and per zone on public transport $\left(E x_{i}\right)$, the trips made in public transport per zone in a typical day $\left(T_{i}\right)$, and the average monthly household income per zone $\left(Y_{i}\right)$. As the Mobility Survey represents a one typical working day, we considered 22 workdays per month $(k=22)$. Average household income and travel times are variables and are available directly from the 2011 mobility Survey at the UPZ level. The average 
expenditure in public transport and the public transport trips generated per zone were obtained from Bogotá's Mobility Survey (SDM 2011).

However, considering the socio-spatial distribution of the city, as shown in Figures 1 and 2 , there are considerable differences in travel times, cost and distances, which can also influence affordability. In this regard, we have estimated from the transport model the average number of transfers per zone, calculating the cost of the average trips between different low-income zones. This analysis intends to provide insights on the influence of a system that imposes transfers as a necessary condition for longer trips. A key limitation of observed affordability measures is that if someone needed to make a trip but did not because of financial limitations, then that trip would not be included in his or her transportation expenditure (see \% immobility Table 2 ).

\subsection{Equity}

In addition to the impact of subsidies on job-accessibility and affordability, we wanted to measure their impact on equity. We evaluated the vertical equity (Litman, 2014), which implies that disadvantaged groups (low-income group) must be identified in order to design specific policies in their favour, like subsidies, in order to improve their current transport expenditure conditions. I.e. we want to know if job-accessibility is evenly distributed among income groups. To measure this in the study area, we use a variation of Lorenz curves (Lucas et al., 2016; Grengs, 2015; Delbosc and Currie, 2011) to compare the distribution of accessibility levels by public transport across the population. We assumed that all households of a zone share the same characteristics. The approach to comparing how various income groups experience job-accessibility (before and after subsidies) is to plot accessibility indices against the city share of households by zone across the Bogotá-Soacha region.

To complement this, we explore a recent measure of inequality developed as an alternative to the Gini index for analysing the distribution of income: the Palma ratio. Originally, this indicator is "the ratio of national income shares of the top $10 \%$ of households (richest) to the bottom 40 (poorest). If the richest $10 \%$ in a country earn between them half of the national income, and the poorest $40 \%$ earn one-tenth of the national income, the Palma ratio is 0.5 divided by 0.1 , which is 5 " (Palma, Stiglitz 2016, Palma 2011). Thus, the larger the ratio, the greater the inequality. The reason to isolate this particular ratio instead others, is because Palma found that middle class income almost always accounts around half of national income, i.e., this group have a relatively stable share of national income both across countries and over time.

We build into the principles of the Palma ratio and adapt this indicator to measure if the subsidies improve the job-accessibility to the low-income population. To do this, we classified every zone into the study area according the average household income and its corresponding decile. Then, average accessibility levels were calculated for each group by zone: top $10 \%$ and bottom $40 \%$, for each year. With this information, the our modified ratio was calculated. Such as the Palma ratio can relay better results than the Gini for income, by adopting the overall logic of the indicator for the analysis of accessibility, we can provide better insights considering Gini's relative insensitivity to changes at the top and bottom of the distribution of accessibility, in this case.

This indicator could be a better measure for policy makers to track, as it is intuitively easier to understand. It is also clearer about what needs to change: to close the gap between the poorest and the richest members of a society in any issue. This is important because it 
means that much of the politics of distribution can be summarized by this ratio, through a clear message: e.g., if the ratio is 5.0 , this means that the richest $10 \%$ earn 5 times the income of the poorest $40 \%$.

\section{Scenarios}

To measure the impact of SITP subsidies on accessibility to work, we first built a baseline scenario (2011) using travel times and costs to work by public transport, job location and cost-sensitive parameters observed in 2011. Travel times by public transport in 2015 for alternative scenarios were estimated with a transport demand assignment model developed using VISUM $®$ modelling software (Bocarejo et al. 2016). The model incorporates headway and travel speed data for most of routes of the SITP.

Monetary expenditures (fares) for 2015 were brought to 2011 prices (in COP) using the consumer price index of the Colombian Central Bank. Fares in 2011 for the bus and TM systems were 1,400 and 1,700 COP ( 0.74 and 0.89 USD), respectively. In 2015 , fares were 1,550 and 1,800 which equal 1,384 and 1,607 COP ( 0.73 and 0.85 USD) in 2011 prices, respectively. In real terms, the fares became cheaper than in 2011 , showing fare reductions $1.1 \%$ for TM and $5.5 \%$ for the regular bus. This trend is explained due to a political decision by the city's administration of not increasing public transport fares between 2011 and 2015 despite an increase in inflation during that period ${ }^{4}$.

Data provided by TM and the private operator for fare collection in the SITP (Recaudo Bogotá) was used to determine the average of fare subsidies per zone and per trip (Figure 4). Data on the use on the subsidized of SITP smart cards in 2014 comprises information on the behaviour of 115,600 smart cards' users between January and November 2014. This information was georeferenced by zone using the SISBEN database. This allowed us to pinpoint the locations of beneficiaries who requested the subsidy (the poorest population segment), which unsurprisingly locate predominantly at the periphery of the city, mainly in its southern and western edges (see Figure 2 and 4).

Job-accessibility values were obtained for each zone in the Bogotá-Soacha region for the baseline and alternative scenarios of changes in time and cost. We maintained job opportunities and cost-sensitive parameters constant in all modelled scenarios in order to translate variations in travel features into measurable changes in accessibility levels. In the alternative scenarios, the part of the generalized travel cost function related to travel cost was used to simulate the effect of transport subsidies on accessibility. In order to evaluate the effect of transport subsidies in the accessibility levels, we proposed an alternative scenario (A1), in addition to the baseline scenario (A0):

A0. Accessibility changes without subsidies: This scenario estimates the changes in accessibility between 2011 and 2015, assuming that there are no transport subsidies. The baseline job-accessibility by public transport was estimated by 2011 . In this year, there were only two of the three phases of the TM system in operation alongside the traditional bus system. Neither the SITP nor the extension of TM to Soacha had been implemented.

A1. Accessibility changes with subsidies: This scenario intends to address the question of what would happen if the poorest residents in each zone had access to the subsidies in 2015, regarding the baseline accessibility 2011. As very few residents (in relation of the potentially eligible population) have access to these targeted subsidies in 2014 (with no

\footnotetext{
${ }^{4}$ The consumer price index for the period $2011-2015$ was $15.6 \%$.
} 
practical impacts on accessibility), we part from the assumption that every public transport user in income range 1 travelling pays a subsidized fare. According to the mobility survey in 2011, in Bogotá there are 1,607,618 people belonging to the income range 1 .

Additionally, we want to know would be the effect of the variation of subsidies: This 'scenario' (A2) explores what would happen if the amount of subsidy varies, with respect to the original estimated value of the subsidy (Figure 4). That is, how does accessibility change if the fare subsidy value is changed in a percentage? And, what are the expected effects of these changes in accessibility, and how these changes are related to income level?

The scenario structure built for the research produces the following outputs: i) accessibility levels comparison in 2011 and 2015 without transport subsidies (A0); ii) accessibility levels comparison in 2011 and 2015 with subsidies. In 2015, the SITP was implemented (mostly) and operating transport subsidies for the income range 1 residents (A1); and iii) variation of amount of average subsidy by income group (A2). These scenarios allow to compare accessibility levels over time and evaluate existing transport subsidies and their efficiency for zones with different levels of income. Additionally, we present an equity analysis using what we will refer to as the pseudo-Palma ratio ${ }^{5}$ for three situations 2011 and 2015 (no subsidies), and 2015 with subsidies for all population in income range 1.

\section{Results}

Figure 5 (left) shows the $\beta_{i}$ parameters that reflect generalized travel cost deterrence. These results evidence higher travel costs parameters in the city expanded centre and wealthier zones. This means that an eventual increase of average travel costs in public transport (time or fares) would involve further reductions in the number of accessed workplaces in zones with more negative coefficients in comparison with the rest of the urban area. Results are consistent with previous findings (Guzman, Oviedo \& Rivera 2017, Bocarejo et al. 2016, Bocarejo, Oviedo 2012) where people with higher income levels are more susceptible to use other transport modes (like private car) as a consequence of less favourable travel costs in public transport.

Figure 5 (right) shows the proportion of income range 1 households by zone. As initially suggested from Figure 2, the poorest population is located in the southern borders of the city and in Soacha. According to the assumptions of scenario A1, accessibility levels were modelled with this as the target population using demand transport subsidies.

Figure 5. Cost sensitivity parameters and population to targeted subsidies Source: Own elaboration.

Figure 6 shows the changes between 2011 and 2015 regarding travel times and costs. These cost reductions are explained by a real decrease in the public transport fares in 2015 (discounting inflation) in comparison with fares in 2011. These conditions allow for

\footnotetext{
5 The indicator maintains the overall logic of the Palma ratio but modifies the methodology of calculation given the characteristics of accessibility distribution compared to income. We compute average accessibility weighted by population for the zones belonging to Decile 10 and for those belonging to Deciles 1 to 4 . Then we calculated the ratio. By controlling for population size, we estimate the ratio of group accessibility, which we believe is more easily interpreted and corresponds to a better measure of equity in the distribution of accessibility
} 
improvements in the overall accessibility results when comparing the two years side by side. When introducing subsidies to the monetary part of generalized travel cost function, accessibility levels improve even further.

Figure 6. Travel times and travel costs changes between 2011 and 2015 Source: Own elaboration.

After potential accessibility was calculated for each zone, normalized values were calculated by dividing each zone's value by the mean value (weighted by population) for Bogotá and Soacha, as shown in Figure 7. These normalized values allow for a focus on relative differences between zones rather than the absolute values, which are largely meaningless except in a relative sense (Handy 1994).

Modelling results show meaningful reductions in transport costs in all scenarios. The expanded centre has relatively higher accessibility levels in comparison with surrounding zones and the periphery. This reflects the relative importance of jobs at shorter distances according to the potential measure. Furthermore, peak accessibility levels by public transport can also be found in the expanded centre. However, the spatial distribution of changes in potential accessibility in scenario A1 (Figure 7) shows how socially vulnerable zones are amongst the main beneficiaries, in terms of accessibility, of the SITP implementation and fare reductions. The case of Soacha is striking because of the large effect that TM had on the overall accessibility of the municipality even despite this area is not being covered by the transport subsidy policy due to jurisdictional boundaries of the policy (the subsidy is an initiative of the city government of Bogotá and only applies within its administrative boundaries). These results are consistent with other studies that have shown that BRT systems able to facilitate equity among urban populations, although there are still some key issues that need to be addressed, like better integration with other public transport systems, to improve its social impacts (Venter et al. 2017).

Figure 7. Job-accessibility changes without and with transport subsidies (A0 and A1) Source: Own elaboration.

In general, results of these two scenarios show a general improvement in job accessibility levels in the urban periphery and low-income zones (of course, much more A1 than A0). This is an important result in terms of social spatial equity and supports the premise of continuing the policy of subsidies for the lowest income population. Such is an expected result insofar as the subsidy is alleviating the economic costs of a considerable share of the demand. However, the distribution of the effects of the subsidy, particularly considering the differences in cost sensitivity parameters between rich and poor, shed some light on the positive results in terms of redistribution of a comparatively low investment in individual mobility conditions in low-income and peripheral areas of Bogotá.

Such a finding is further supported by results of scenario A2. Figure 8 (left) shows the sensitivity analysis of accessibility impacts according changes in a percentage value of subsidies within a range of $-100 \%$ and $+100 \%$ regarding the accessibility value in 2015 , scenario $A 1^{6}$. One of the most relevant findings, considering the socio-spatial distribution of the study area and the visible levels of segregation of low-income population is that transport

\footnotetext{
${ }^{6}$ Just for population belonging to income range 1 .
} 
subsidies are most efficient and effective in low-income zones. Zones with average income range between 3 and 4 , are practically insensitive to changes in the value of subsidies: regardless how much of the fare is subsidized, accessibility changes are lower than $6 \%$. In wealthy zones, this effect is less than $2 \%$. Results also show that subsidies' effects on accessibility are not symmetric (i.e., an increase of $60 \%$ in the baseline subsidy, improves accessibility levels for low-income population by $8 \%$; a reduction of the same magnitude, decreases accessibility by $7 \%$ ).

Figure 8. Job-accessibility changes with subsidies (A2) Source: Own elaboration

Figure 8 (right) shows the variability of the estimator of the average accessibility change is observed when the subsidies are introduced. Bootstrapping techniques (Chernick 2007) were used to infer the distribution of the estimators by income levels, considering the assumptions of the model used. The results presented in this graph show that the accessibility changes are significantly different by income group. They also show that improvements in accessibility are greater for zones that belong to the lower income group. Note that for each zone, the effect depends on the subsidy amount, the relationship of the subsidy with the generalized travel cost function, and additionally the relationship between the monetary cost and travel times for each zone. In summary, this result proves that the subsidies have a significantly, greater and different impact on the low-income segment.

This is related to the large concentration of low-income households in specific areas of the city, suggesting the need for a pre-targeting mechanism that allows to incorporate spatial dynamics into the beneficiary selection. These results can also serve as strong evidence about the importance of adequate targeting mechanisms in transport subsidies that allow maximization of accessibility benefits while preventing large inclusion errors and financial strain, or regressive effects (Serebrisky et al. 2009).

Table 3 shows the aggregated results of accessibility scenarios as the average of all region (Bogotá and Soacha) compared with accessibility levels estimated by 2011. These results are composed by average travel time (work purposes) in public transport and average transport costs (weighted average between regular buses and TM). The results of potential accessibility are explained by the generalized travel cost decay: roughly $60 \%$ of the zones have a generalized travel cost value shorter than $90 \mathrm{~min}$. Using impedance function, the quantity of jobs within reach by public transport is reduced, particularly for zones which have high generalized travel cost values.

Table 3. Average job-accessibility improvements (baseline 2011)

Potential accessibility reflects the effects of both the spatial distribution of opportunities in the city and the features of urban transport in relation to characteristics of the population. Results in Table 3 suggest potential changes in travel features for public transport that, all other variables constant, may influence mode choice in low-income and other zones of the city. In order to understand better the accessibility variations between 2011 and 2015, it should be considered that in 2015 , public transport ridership increased $23.6 \%$ compared to 2011 (5.2 million of daily trips). This includes an increase of $53 \%$ in TM demand, mainly due to the new trunk corridors (phase 3 ). The rest of motorized trips had an increase of $20.2 \%$. This significant demand increase probably influenced the average travel times increase, despite the improvements in the public transport system. 
Although this requires further exploration using supplementary data and additional estimations of parameters governing mode choice, these results serve to highlight the relevance of incorporating supply-side variables in the exploration of targeted urban transport policies. Under the outlined conditions, the subsidies may make public transport more attractive over other transport modes, which can be the first in a set of evidence supporting the need for more research about employment location, income levels and accessibility's relationship with transport use.

Regarding affordability, Table 4 shows that average observed affordability index for Bogotá and Soacha in 2011 is below $14 \%$. It should not be forgotten that this index does not account transport costs in other transport modes. The results show that low-income population proportionally spends 5 times more that population in wealthy zones. In the scenario with transport subsidies in 2015 (A1), no visible improvement relative expenditure between socioeconomic groups is observed (4.4 times). In this scenario, all income groups show lower levels in the estimated affordability index, which indicates less financial stress for everybody. However, the most benefited in this issue are the people who reside in mediumincome zones. The spatial results in Figure 9 complements the results of Table 4, showing that public transport subsidies have greater impact in the periphery of the city, mainly in the west and south-west borders. Here, we do not use scenarios (because the scenarios just take into account changes 2011/2015). The affordability indices were calculated for 2011 (no subsidies) and 2015 (with subsidies).

\section{Table 4. Public transport affordability indices classified by income groups}

When using the information declared in the 2011 mobility survey regarding the value spent on public transport, and the number of trips made by the poorest population (range 1), we estimate that this group spends USD 17.08 million per month on their trips ${ }^{7}$. With subsidies in place, the total paid cost would be USD 9.03 million. This implies an average saving of $5.2 \%$ for these households, with respect to their income. Although it also implies a cost for the city of USD 8.05 million per month.

The difference between maps in Figure 9 reflects population in low and medium-income zones could increase their public transport trip rates in about one fifth. This also means that although in scenario A1 transfers are charged, transport subsidies significantly alleviate the household expenditure in public transport.

Figure 9. Public transport affordability indices per zone Source: Own elaboration

In terms of equity, we calculated the normalized values of accessibility (weighted by population) for deciles 9 to 10 and 0 to 4 by zone (top $10 \%$ and bottom $40 \%$, respectively), in line with previous studies applying a similar overall logic than that of the Palma ratio to income. Then, we calculate a pseudo-Palma ratio for each case (2011 and 2015 -no subsidies- and 2015 with subsidies) as shown in Table 5 . The use of this pseudo-Palma ratio is proposed as an appropriate measure for reflecting the effects on equity of the targeted subsidy for citizens in the lower tier of the income distribution. There is not widespread use of equity measures in relation to accessibility, with a few examples of the use of Gini indices and Lorenz curves (Jang et al. 2017, Guzman, Oviedo \& Rivera 2017,

\footnotetext{
${ }^{7}$ Assuming 2 trips per day and 22 workdays per month.
} 
Lucas et al. 2016), which were also initially developed for examining income distribution. Although the Palma ratio was originally intended as an alternative to these measures in examining distribution of income, the principle of the measure -which supports a focus on the lowest and highest tiers of income distribution-, can be applicable to distribution of other quantifiable measures of finite assets such as accessible opportunities.

\section{Table 5. Pseudo-Palma ratio}

Results show that in 2011, the top $10 \%$ in Bogotá enjoyed in average, 1.4 times more accessibility that bottom 40\%. In 2015 (with the subsidies in place), the gap diminished by $13 \%$. This shows the potential positive effects of targeted transport faring policies for the most socially vulnerable populations in relation to equity. An inclusive transport policy, such as targeted subsidies, should target the bottom-tier of the income pyramid in the city, increasing accessibility levels of the poorest $40 \%$ of Bogotá.

In order to complement the above and to better understand the effect that subsidies would have on the accessibility distribution by public transport, we present the concentration curve (Wagstaff, Paci \& van Doorslaer 1991) under the two scenarios analysed (Figure 10). This curve plots the cumulative percentage of the accessibility (y-axis) against the cumulative percentage of the population, ranked by income, beginning with the poorest, and ending with the richest. If every zone, irrespective of it average income, has exactly the same value of the accessibility, the concentration curve will be a 45-degree line (grey line).

\section{Figure 10. Accessibility concentration curve}

Source: Own elaboration

The concentration curve for AO scenario lies below the line of equality, indicating that low accessibility values are concentrated among the poor. The A1 scenario curve lies everywhere above that of $\mathrm{AO}$, indicating there is less inequality with the transport subsidies in place, than without it. Results also show that for the poorest half of the population $(<50$ th percentile), the accessibility has a better (evenly) distribution: The A1 curve proceeds in a straight rise, with a relatively constant slope.

To see the differentiated effects according to the income group, Figure 11 shows the distribution of accessibility and the calculation of the Gini index (Gini index $=0.212$ in A0). This figure illustrates the approach, showing the accessibility index on the y-axis against the percentile of population by zone on the x-axis. The results shows greater inequalities, as can be seen by the contrasting shapes of the three lines. In the AO scenario, up to the 30th percentile of high-income population experience high levels of accessibility (above average), suggesting great difference between the other income groups. This distribution contrasts with the curves of the other income groups, where more inequitable distributions are obtained. In these cases, about $50 \%$ of the population of these two income group experience lower accessibility levels than the average. For the low-income group, it shows that the curve for $\mathrm{A} 1$ scenario lies above that for $\mathrm{A} 0$. The result confirms that the subsidy to poorest population (income range 1) improve the accessibility levels for this segment. I.e., is an effective pro-poor policy. In the other income groups, no significant difference is observed for both scenarios.

Figure 11. Cumulative distribution curves and Gini indices A0 and A1 


\section{Source: Own elaboration}

As shown, there is an improvement in equity in the distribution in accessibility through improvements in the affordability of low-income population. Scenario A1 (Gini index $=0.225$ ) shows how the scaled-up subsidy can bring more low-income people closer to the mean accessibility in the city. There is a marginal increase also in the accessibility of high-income zones that despite having a proportionately low poor population, concentrates enough for them to benefit from the subsidy and the affordability benefits. Although the Gini index deteriorates slightly, the population of low-income zones benefits significantly.

\section{Discussion}

The research highlighted the usefulness of accessibility estimations and scenarios in the analysis of socially, spatially and economically differentiated outcomes of urban transport, even within the limited scope of access to jobs. Although the results are to be expected given the nature of the policy under examination, exercises like the one presented are not often carried out nor are discussed openly in academia or practice. Economic evaluations are not easily accessible or understandable by non-specialist audiences, constraining participation and inclusion. This paper presents simple, accessible and reliable information, used by most practitioners in the sector, to highlight the potential benefit of a transport policy with a social focus.

The rationale behind potential accessibility is complementary to traditional transport assessment approaches as argued in previous research (Guzman, Oviedo \& Rivera 2017, Bocarejo, Oviedo 2012). Accessibility allows to build a better-informed perspective of the urban distribution of both the determinant factors in the use of transport and its immediate benefits in relation to access to some of the opportunities in the city. However, for these estimations to enrich debates on the contribution of urban transport to issues like social inclusion, it becomes necessary for them to incorporate the affordability dimension, which can be a great explanatory factor in lack of access for specific social groups. Within its own limitations, the use of accessibility metrics provides a valuable middle ground for starting discussions between different stakeholders and enable a good understanding of larger spatial dynamics. More specific data, both quantitative and qualitative, is however required at a lower level of aggregation for the detailed exploration of travel practices, preferences and perceptions, particularly in socially vulnerable populations, considering the complexities involved in travel behaviour.

Many cities in the Global South are facing similar conditions to those of Bogotá's in relation to the challenges of restructuring urban public transport; reduce north-south divides between socioeconomic groups in their populations, and reducing the accessibility gap between the poor and the rest of the population. These results can serve as additional evidence regarding the potential of both targeted and general policies for improving affordability (i.e. as maintaining fares constant in real prices) in a context like Bogotá and Soacha's. The paper focuses on targeted transport policies, funded within the sector. The authors do not have the information for comparing other sectors, nor is it relevant as other social policies are in place to address affordability issues in health, education and pensions (i.e. Bogotá has a programme of free access to primary and secondary schools). The evidence and arguments presented are to be interpreted within decision-making avenues in the transport sector, highlighting a policy action in the transport agenda to address inequalities in a context such as Bogotá. Development policies have historically given priority to most sectors and physical infrastructure, such as the prioritisation of the expansion of TM and implementation of the 
SITP, but not often affordability of transport. The improvements in coverage resulting from the integration of public transport, and the affordability benefits from the subsidies, are intermediate requirements for enabling low-income communities to access more and better opportunities for health, education and employment. From a transport policy perspective, we are interested in providing additional arguments and evidence for thinking differently about what investment mechanisms can contribute to closing the gaps between people in better social and geographical positions and the poor.

The exploration of accessibility implications in other cities in Latin America and other developing cities of similar policies could help shaping future agendas and practices in relation to improving the living conditions of the urban poor through transport. The evidence from this case study shows the relevance of additional policy mechanisms, like subsidies, for the redistribution of the costs and benefits of both the city's configuration and that of its transport network. However, a pro-poor public transport subsidy policy aimed to improving accessibility is not to be confused with another aimed to encouraging the use of the public transport; since there is evidence that this does not work (de Grange, Troncoso \& González 2012).

There is a clear clustering of poverty and opportunities in the Bogotá-Soacha region, which constrains even further mobility for low-income workers already under purchasing power restrictions. The implementation of the SITP has gone a long way in improving service conditions throughout the city and has arguably entailed some additional benefits beyond the scope of this research. However, probably one of the most relevant benefits from the development of the system in the context of this research is that the implementation of fare collection through smart cards has made possible to operationalize a targeted subsidy for users in specific conditions of poverty and vulnerability. This represents a radical change in the conditions for delivery of transport subsidies and, as in this case, also allows to exploit existing targeting mechanisms as SISBEN.

Results also show that for the poor currently withstanding very high travel times to reach jobs that are increasingly located in the expanded centre, an alleviation of their monetary expenditure can be instrumental in increasing their individual potential accessibility. Further research on this policy is required to establish to what extent the benefits of the subsidy could also be directly or indirectly transferred to other members in the household (i.e. by reducing overall household travel expenditure), and whether this can also increase accessibility to other types of opportunities.

The concept of equity reflects a concern to reduce systematic discrimination and marginalisation. This paper addressed traditional and more recently applied equity metrics to a non-income outcome variable such as accessibility, to estimate the contribution of public transport fare policies to the reduction of systemic inequalities between different social groups. The analysis using the pseudo-Palma Ratio and Gini Index allow for analysis beyond arithmetical imbalances in the distribution of accessibility, which has both a moral and normative dimension (DeVerteuil 2009). First, the Gini index allowed to visualize and interrogate the distribution of accessibility by distinctions of personal attributes, such as location and income, which in Latin American cities tend to be correlated. Such imbalances are the reflection of levels of (sometimes unintended) discrimination towards some groups that become disproportionally better or worse off than others in relation to elements of social advantage/disadvantage such as income, wealth, and opportunities. 


\section{Conclusions}

Results suggest a relevant potential of pro-poor transport policies, particularly in relation to improving affordability and close the gap between rich and poor (Figure 8 and 10). Bogotá's efforts in relation to this programme have many positive elements that should be highlighted and discussed in international circles such as the use of a targeting mechanism for social policy, applied in the transport sector for allocating concessionary fares and its distributional effects on reducing inequalities in accessibility.

The paper used accessibility, affordability and equity metrics to assess pro-poor subsidies in public transport. Although the paper's results are not new from a methodological standpoint, the estimations and discussions posed in the article are a necessary step in the promotion of transport policies with stronger social focus. The exercise presented is aligned with the moral concerns regarding equity and it proposes the use of evidence, that although logical, is not often considered in the toolkit for transport policy appraisal and development. In this regard, the paper puts forward a critical analysis of easily understandable and accessible evidence that supports what should be an obvious result but that unfortunately has not been integrated into mainstream public transport policies: that targeted subsidies are an effective way to redress longstanding social and spatial inequalities in cities with high socioeconomic segregation such as Bogotá. In these lines, by documenting and assessing a policy that has been implemented in very small scales in the Latin American region, and through the use of readily available and easily understandable information we provide an evidence base that can counterbalance traditional technical or economic-efficiency-related arguments that have historically written off similar policies.

The application of the pseudo-Palma ratio allows to reflect the spirit of the moral dimension of inequality, emphasising on those better -and worse- off. The contribution of the application of such a metric allows us to differentiate distributions that can be unjust and unequal, from others can be equal but not equitable, informing redistributive policies that can allocate more resources to those social groups with higher needs. From an equity perspective, public transport subsidies have the potential of playing a significant role as social policies, redressing structural inequalities that are determined in relation to varying levels of social advantage or disadvantage, and allowing disadvantaged groups to improve their chances to access opportunities for further economic and social development. Further research is needed in the area of equitable transport policies and the implications of the use of metrics such as Gini and the pseudo-Palma ratio, as well as other potential equity metrics yet to explore in relation to outcomes of urban transport policy.

\section{Acknowledgements}

We would like to express our gratitude to the World Bank, for the funding a project called "Accessibility and affordability impact evaluation of Bogotá's SITP", which was the origin for the development of this paper.

\section{References}

Ardila, A. (2005) 'La olla a presión del transporte público en Bogotá', Revista de Ingeniería, 21, pp. $56-67$.

Armstrong-Wright, A. and Thiriez, S. (1987) 'Bus services: reducing costs, raising standards'. World Bank technical paper \# WTP 68. The World Bank, Washington, DC 
Bocarejo, J.P., Escobar, D., Oviedo, D. and Galarza, D. (2016) 'Accessibility analysis of the integrated transit system of Bogotá', International Journal of Sustainable Transportation, 10(4), pp. 308-320.

Bocarejo, J.P. and Oviedo, D.R. (2012) 'Transport accessibility and social inequities: a tool for identification of mobility needs and evaluation of transport investments', Journal of Transport Geography, 24, pp. 142-154.

Bruinsma, F. and Rietveld, P. (1998) 'The Accessibility of European Cities: Theoretical Framework and Comparison of Approaches', Environment and Planning A, 30(3), pp. 499521.

Chernick, M.R. (2007) 'Bootstrap Methods: A Guide for Practitioners and Researchers'. Second Edition. John Wiley \& Sons, Inc. ISBN: 9780470192573

Dávila, J.D., Gilbert, A., Brand, P., Rueda, N. and Coupe, F. (2006) 'Housing and land for the urban poor. Case studies of Bogotá-Soacha and Medellín'. Unpublished report for World Bank Cities Alliance and Departamento Nacional de Planeacion. Bogotá.

de Grange, L., Troncoso, R. and González, F. (2012) 'An empirical evaluation of the impact of three urban transportation policies on transit use', Transport Policy, 22, pp. 11-19.

Delbosc, A. and Currie, G. (2011) 'Using Lorenz curves to assess public transport equity', Journal of Transport Geography, 19(6), pp. 1252-1259.

DeVerteuil, G. (2009) 'Inequality', in Kitchin, R. and Thrift, N. (eds) International Encyclopedia of Human Geography, Elsevier, Oxford.

Di Ciommo, F. and Shiftan, Y. (2017) 'Transport equity analysis', Transport Reviews, 37(2), pp. 139-151.

El-Geneidy, A.M., Legrain, A. and Buliung, R. (2016) 'Travelling fair: Targeting equitable transit by understanding job location, sectorial concentration, and transit use among lowwage workers', Journal of Transport Geography, 53, pp. 1-11.

Geurs, K.T. and van Wee, B. (2004) 'Accessibility evaluation of land-use and transport strategies: review and research directions', Journal of Transport Geography, 12(2), pp. 127140.

Gilbert, A.G. and Ward, P.M. (1982) 'Residential Movement among the Poor: The Constraints on Housing Choice in Latin American Cities', Transactions of the Institute of British Geographers, 7(2), pp. 129-149.

Grengs, J. (2015) 'Nonwork Accessibility as a Social Equity Indicator', International Journal of Sustainable Transportation, 9(1), pp. 1-14.

Guzman, L.A. and Bocarejo, J.P. (2017) 'Urban form and spatial urban equity in Bogota, Colombia', Transportation Research Procedia, 25C, pp. 4495-4510.

Guzman, L.A., Gomez, A.M. and Rivera, C. (2017) 'A Strategic Tour Generation Modeling within a Dynamic Land-Use and Transport Framework: A Case Study of Bogota, Colombia', Transportation Research Procedia, 25C, pp. 2540-2555. 
Guzman, L.A., Oviedo, D. and Bocarejo, J.P. (2017) 'City profile: The Bogotá Metropolitan Area that never was', Cities, 60, Part A, pp. 202-215.

Guzman, L.A., Oviedo, D. and Rivera, C. (2017) 'Assessing equity in transport accessibility to work and study: The Bogotá region', Journal of Transport Geography, 58, pp. 236-246.

Handy, S. (1994) 'Regional Versus Local Accessibility: Implications for Nonwork Travel', Transportation Research Record, 1400, pp. 58-66.

Hansen, W.G. (1959) 'How Accessibility Shapes Land Use', Journal of the American Planning Association, 25(2), pp. 73-76.

Hernandez, D. and Falavigna, C. (2016) 'Assessing inequalities on public transport affordability in two latin American cities: Montevideo (Uruguay) and Córdoba (Argentina)', Transport Policy, 45, pp. 145-155.

Hidalgo, D. and Gutierrez, L. (2013) 'BRT and BHLS around the world: Explosive growth, large positive impacts and many issues outstanding', Research in Transportation Economics, 39(1), pp. 8-13.

Jang, S., An, Y., Yi, C. and Lee, S. (2017) 'Assessing the spatial equity of Seoul's public transportation using the Gini coefficient based on its accessibility', International Journal of Urban Sciences, 21(1), pp. 91-107.

Koenig, J.G. (1980) 'Indicators of urban accessibility: Theory and application', Transportation, 9(2), pp. 145-172.

Litman, T. (2014) 'Evaluating Transportation Equity: Guidance For Incorporating Distributional Impacts in Transportation', Victoria Transport Institute.

Loo, B.P.Y. and Chow, A.S.Y. (2011) 'Jobs-housing balance in an era of population decentralization: An analytical framework and a case study', Journal of Transport Geography, 19(4), pp. 552-562.

Lucas, K., Bates, J., Moore, J. and Carrasco, J.A. (2016) 'Modelling the relationship between travel behaviours and social disadvantage', Transportation Research Part A: Policy and Practice, 85, pp. 157-173.

Lucas, K., van Wee, B. and Maat, K. (2016) 'A method to evaluate equitable accessibility: combining ethical theories and accessibility-based approaches', Transportation, 43(3), pp. 473-490.

Oviedo, D. and Dávila, J.D. (2016) 'Transport, urban development and the peripheral poor in Colombia - Placing splintering urbanism in the context of transport networks', Journal of Transport Geography, 51, pp. 180-192.

Oviedo, D., Dávila, J.D. and Levy, C. (2017) 'Constructing well-being, deconstructing urban (im)mobilities in Abuja, Nigeria', in Lucas, K. and Uteng, T. (eds) (Im)Mobilities in the City Creating Knowledge for Planning Cities in the Global South and Postcolonial Cities, Routledge, London.

Palma, J.G. (2011) 'Homogeneous Middles vs. Heterogeneous Tails, and the End of the 'Inverted-U': It's All About the Share of the Rich', Development and Change, 42(1), pp. 87153. 
Palma, J.G. and Stiglitz, J.E. (2016) 'Do Nations Just Get the Inequality They Deserve? The "Palma Ratio" Re-examined', in Basu, K. and Stiglitz, J.E. (eds) Inequality and Growth: Patterns and Policy. Volume II: Regions and Regularities, Palgrave Macmillan UK, London.

Rodriguez, C., Gallego, J.M., Martinez, D., Montoya, S. and Peralta-Quiros, T. (2016) 'Examining Implementation and Labor Market Outcomes of Targeted Transit Subsidies', Transportation Research Record: Journal of the Transportation Research Board, 2581, pp. 9-17.

Saberi, M., Wu, H., Amoh-Gyimah, R., Smith, J. and Arunachalam, D. (2017) 'Measuring housing and transportation affordability: A case study of Melbourne, Australia', Journal of Transport Geography, 65, pp. 134-146.

SDM (2011) 'Encuesta de Movilidad de Bogotá 2011', Secretaría de Movilidad de Bogotá. Bogotá. www.movilidadbogota.gov.co

Serebrisky, T., Gómez-Lobo, A., Estupiñán, N. and Muñoz-Raskin, R. (2009) 'Affordability and Subsidies in Public Urban Transport: What Do We Mean, What Can Be Done?', Transport Reviews, 29(6), pp. 715-739.

Ureta, S. (2008) 'To Move or Not to Move? Social Exclusion, Accessibility and Daily Mobility among the Low-income Population in Santiago, Chile', Mobilities, 3(2), pp. 269-289.

van Wee, B. (2016) 'Accessible accessibility research challenges', Journal of Transport Geography, 51, pp. 9-16.

Venter, C., Jennings, G., Hidalgo, D. and Valderrama Pineda, A.F. (2017) 'The equity impacts of bus rapid transit: A review of the evidence and implications for sustainable transport', International Journal of Sustainable Transportation, pp. 1-13.

Wagstaff, A., Paci, P. and van Doorslaer, E. (1991) 'On the measurement of inequalities in health', Social Science \& Medicine, 33(5), pp. 545-557.

Wiles, J. and Kobayashi, A. (2009) 'Equity', in Kitchin, R. and Thrift, N. (eds) International Encyclopedia of Human Geography, Elsevier, Oxford.

Willoughby, C. (2002) 'Infrastructure and Pro-Poor Growth: Implications of Recent Research'. UK Department for International Development. 


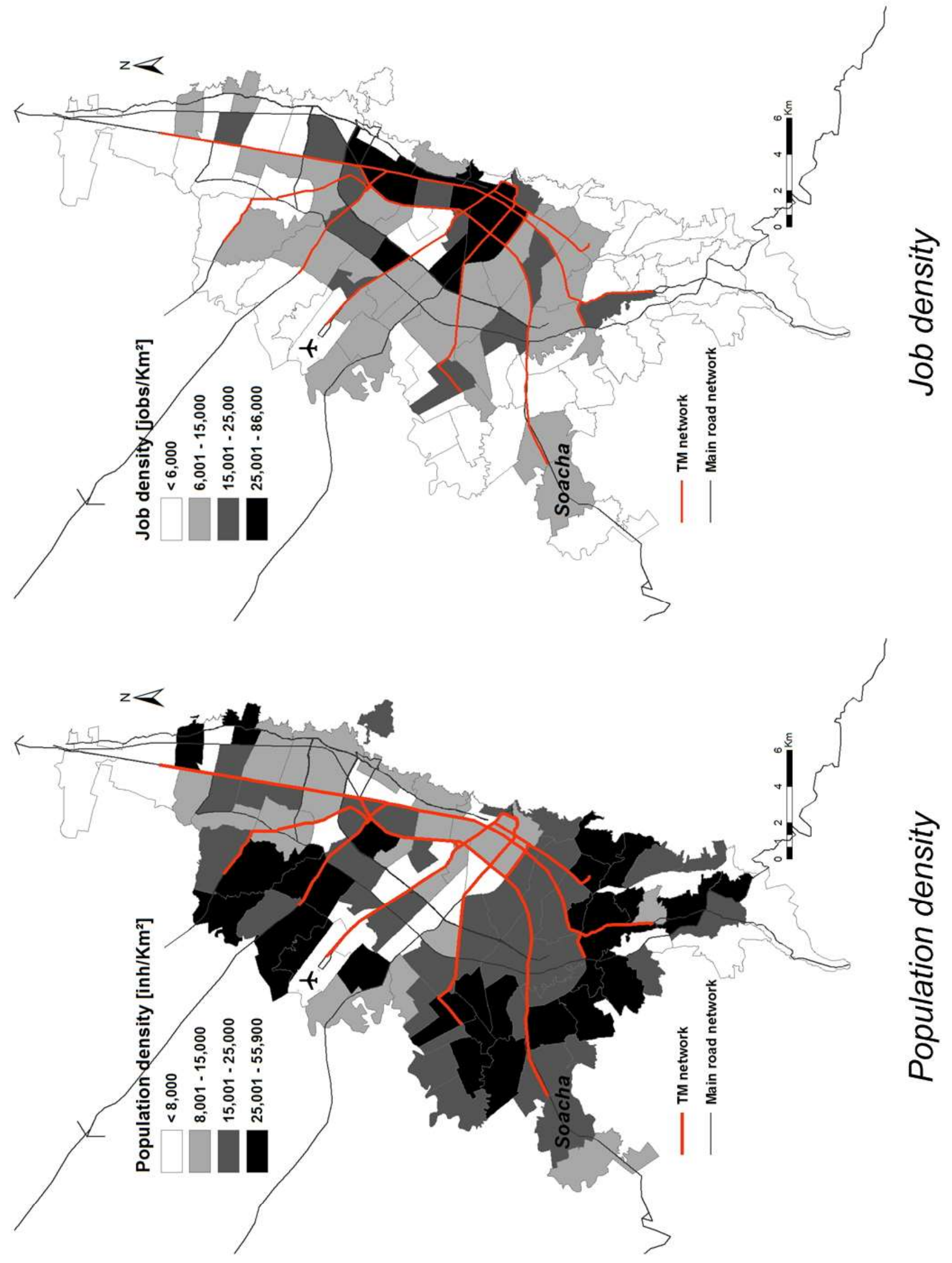



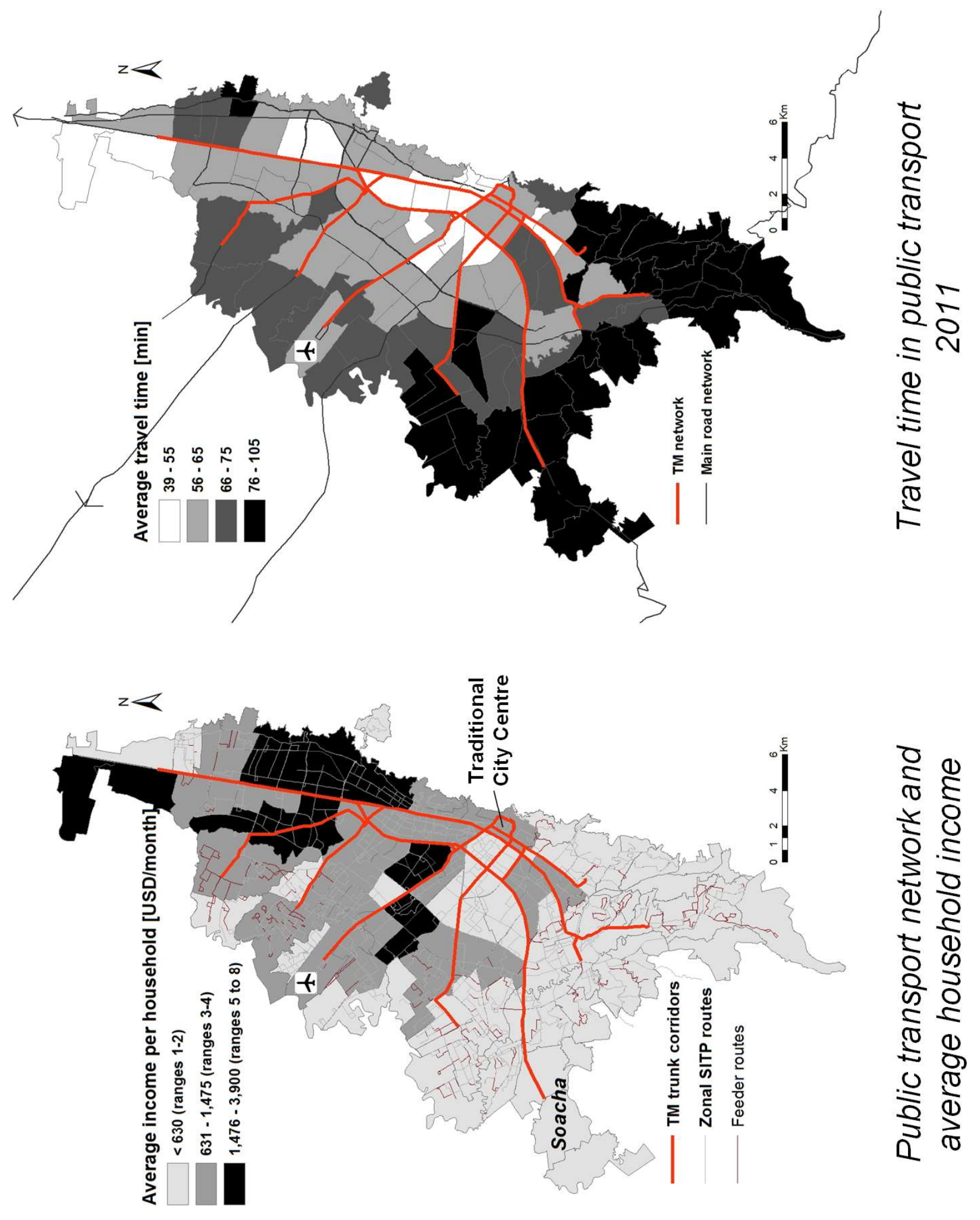


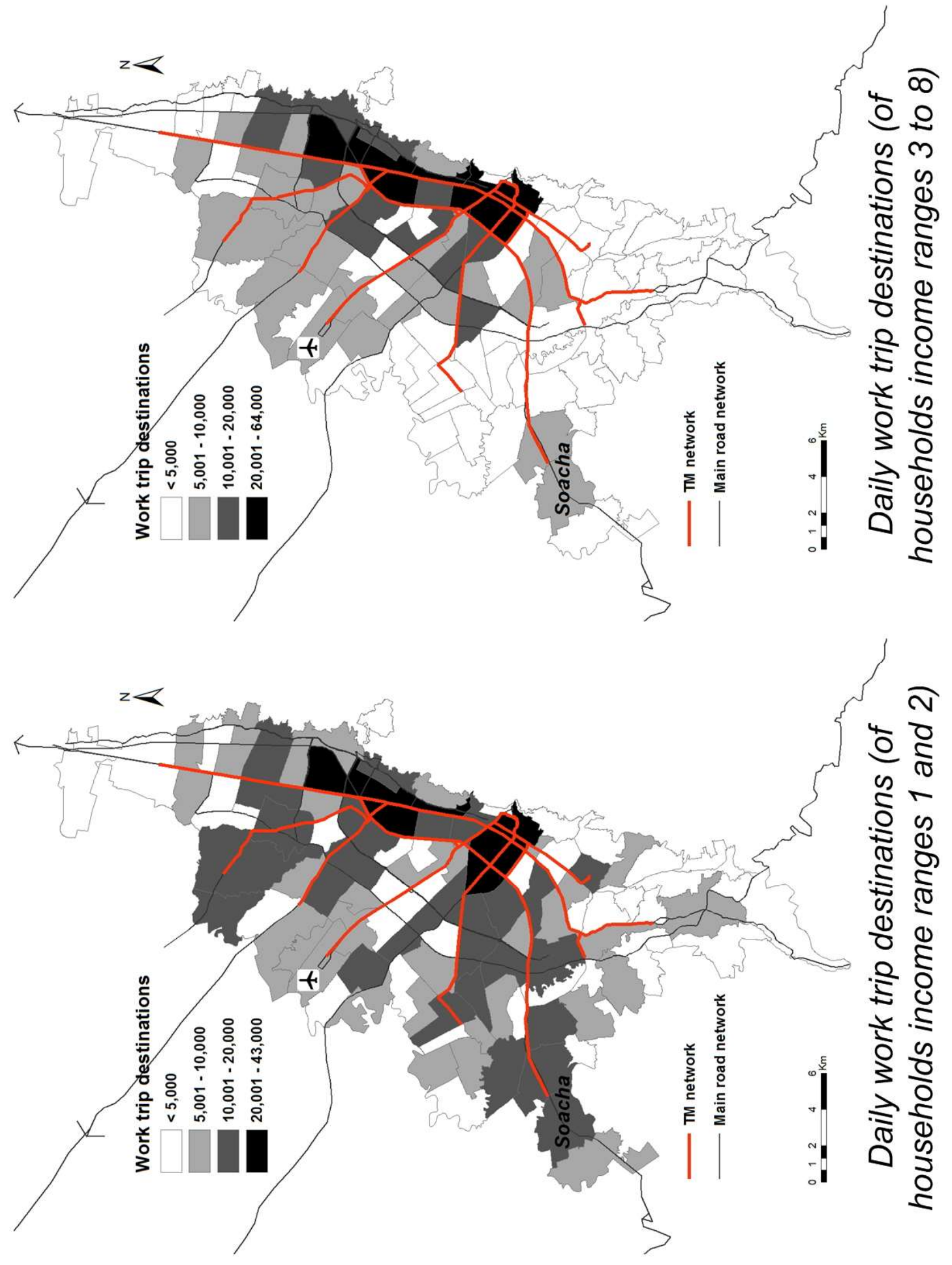




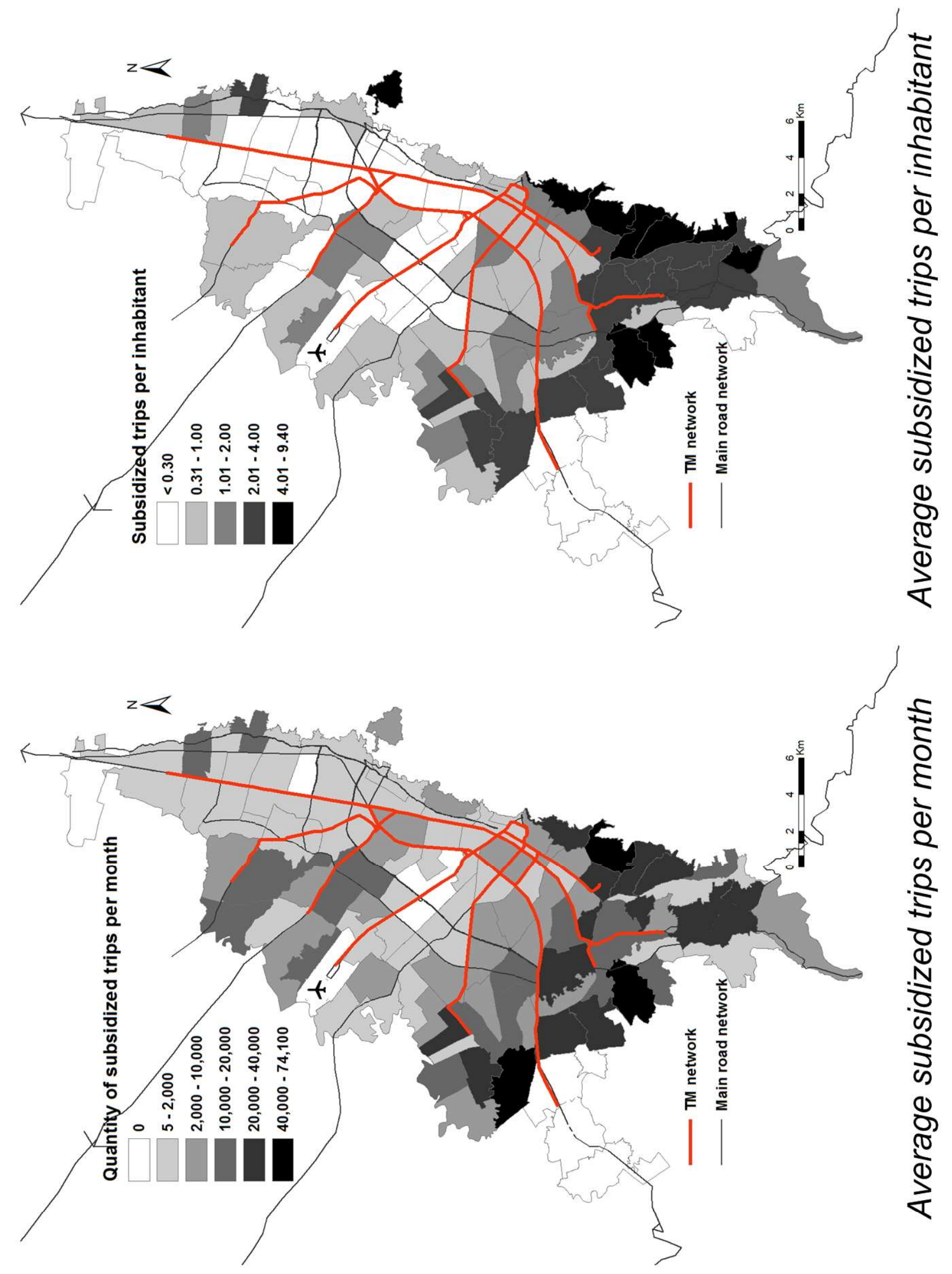






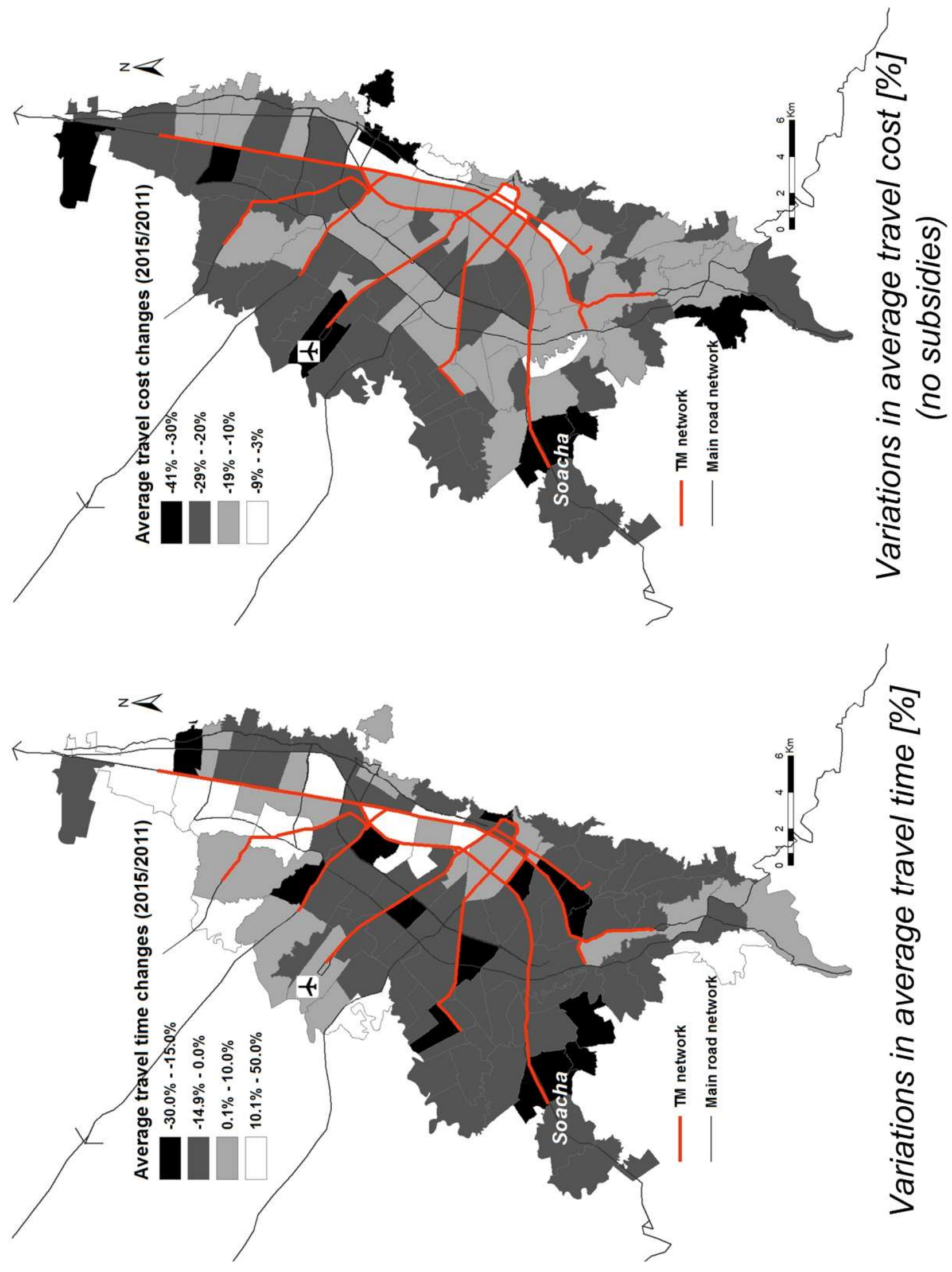




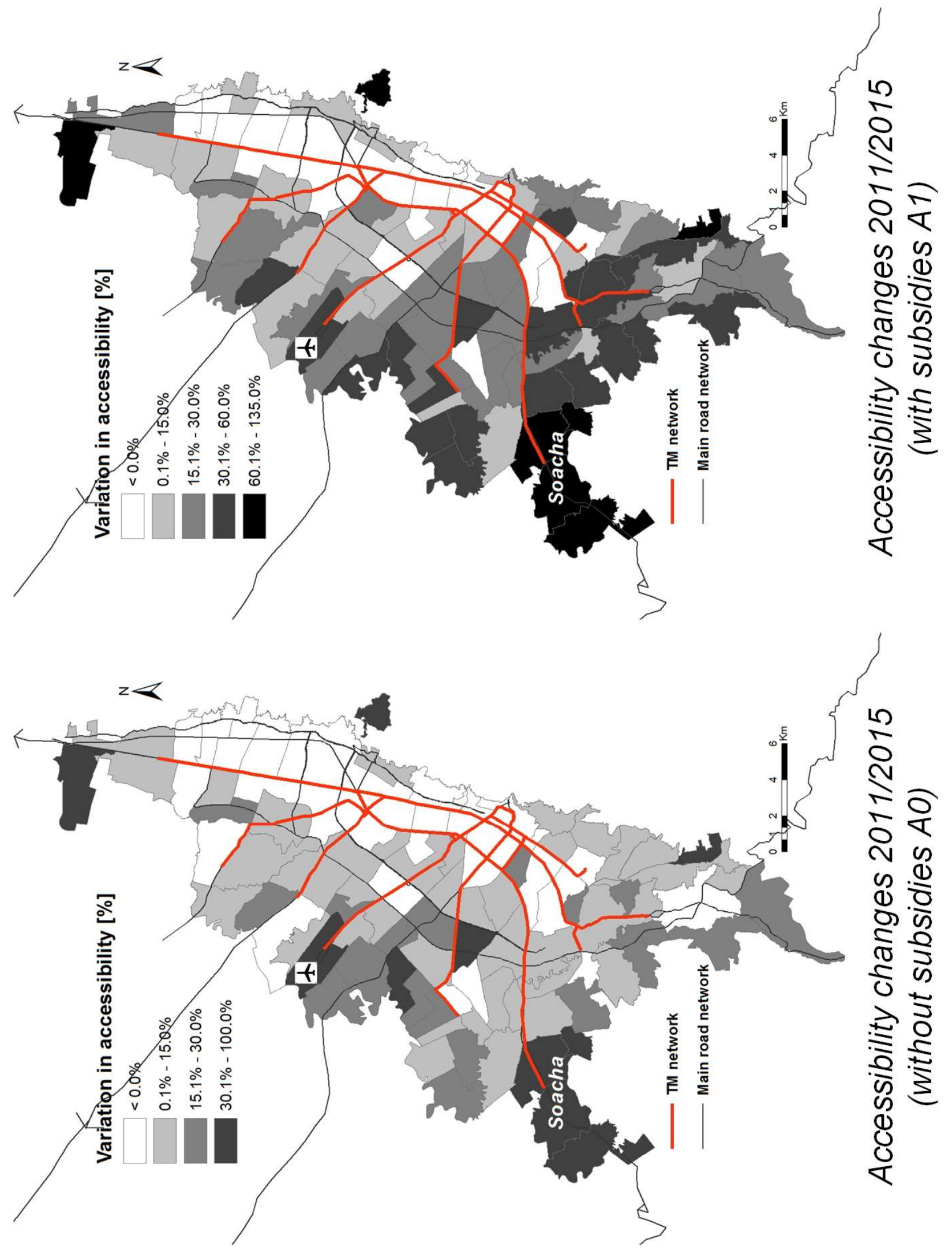



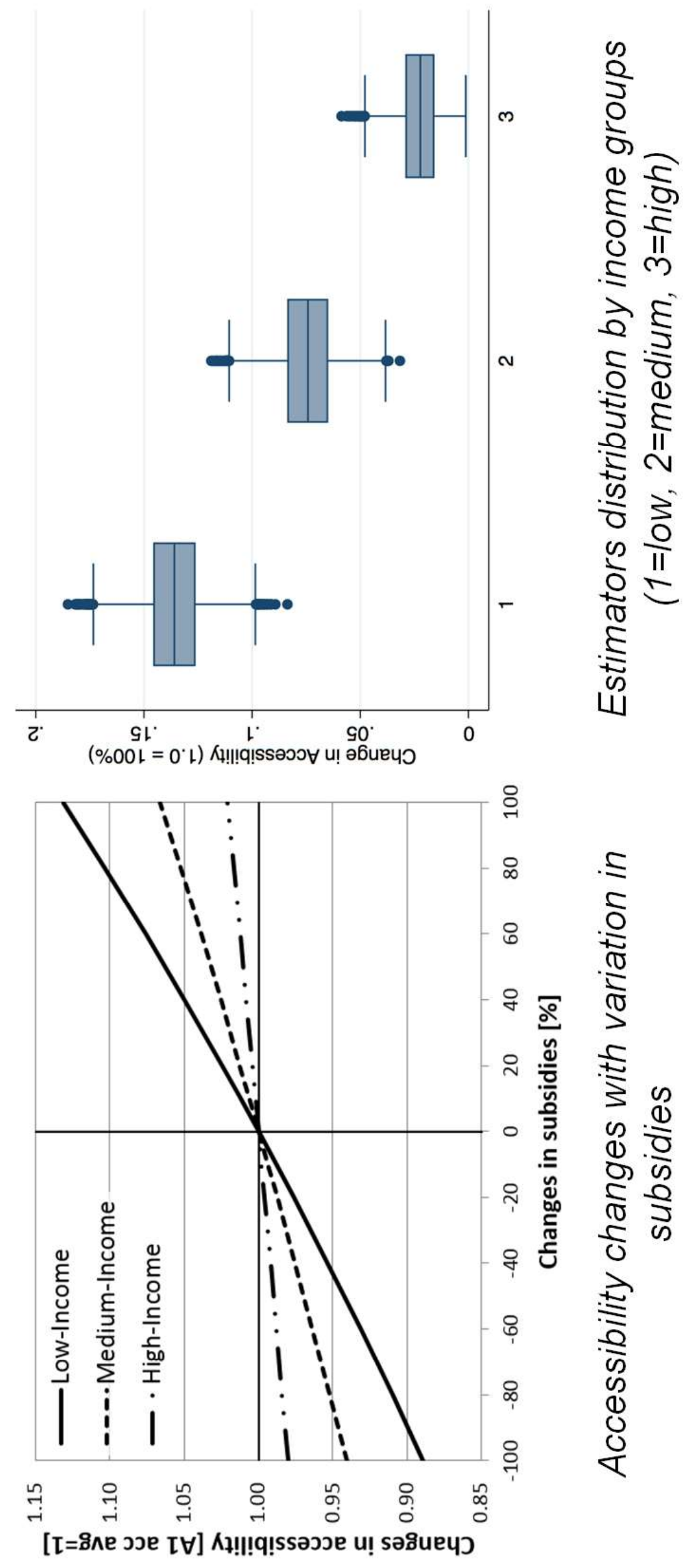


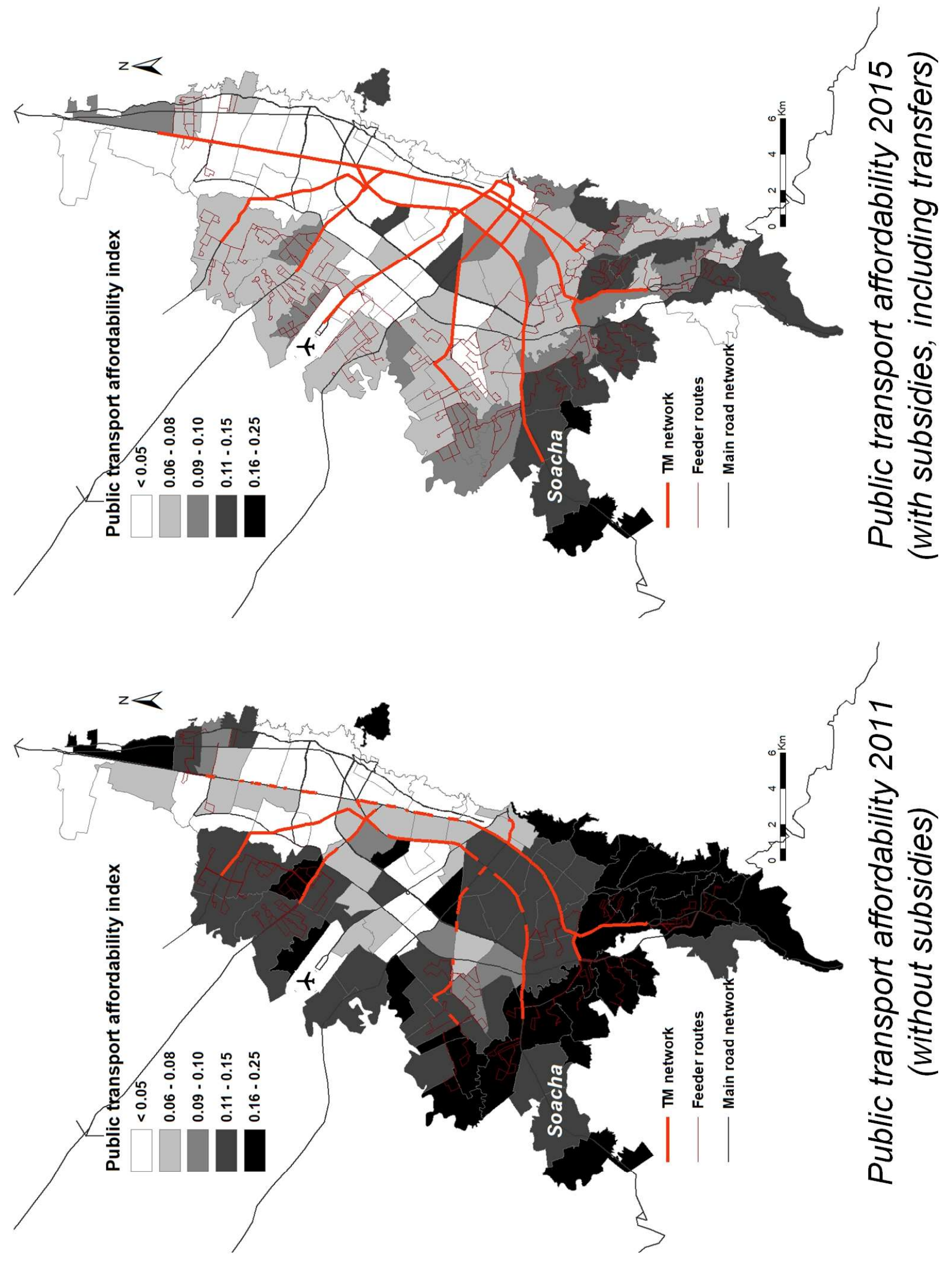




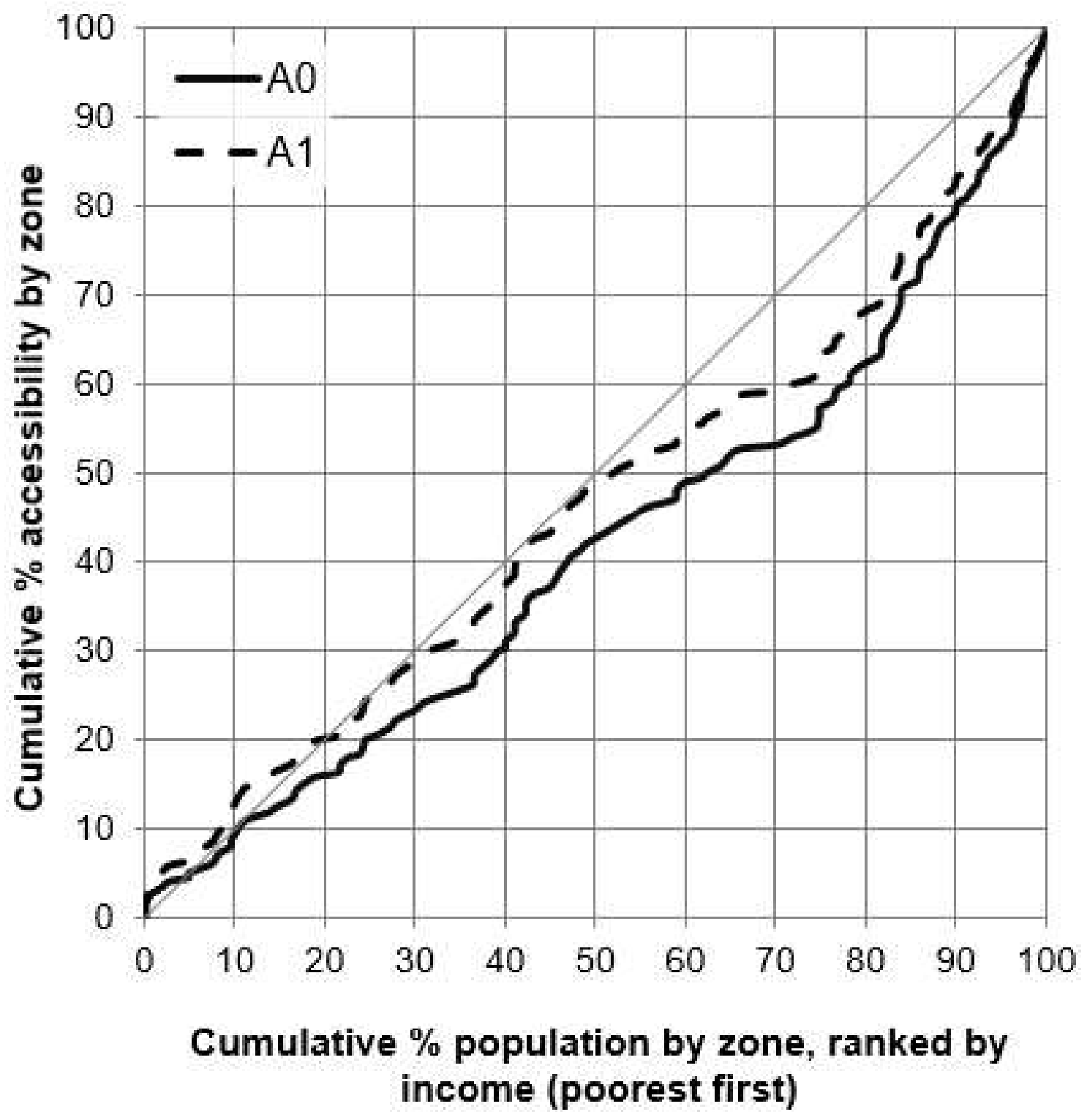



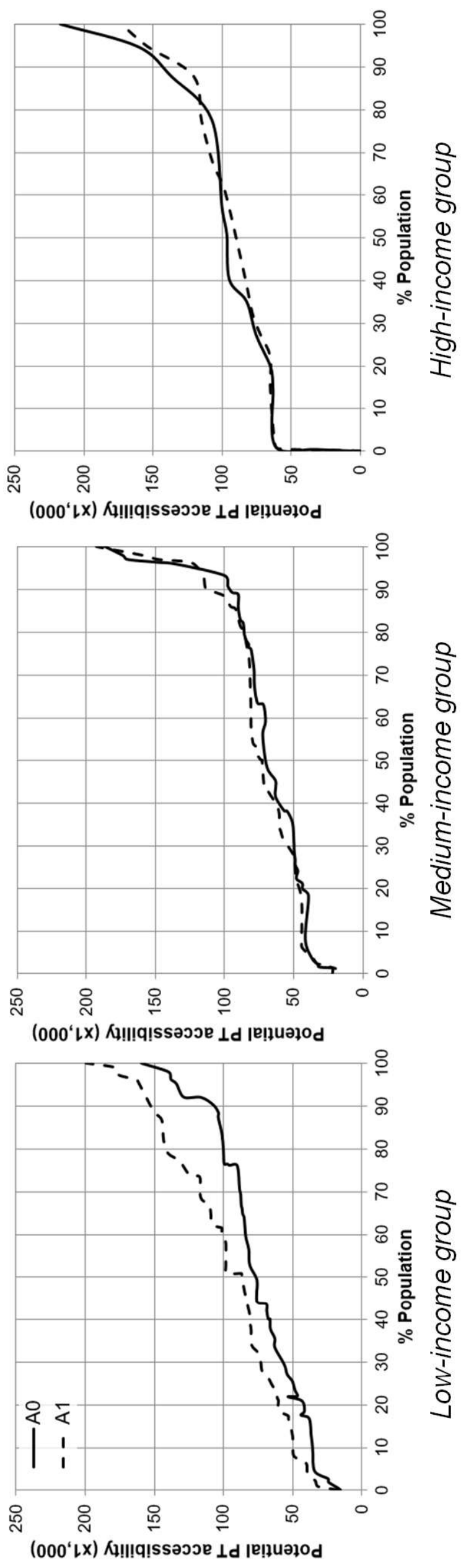
Table 1. Average income per household in USD

\begin{tabular}{|l|c|}
\hline \multicolumn{1}{|c|}{ Income range } & Value \\
\hline Range 1 & $\leq \$ 280$ \\
\hline Range 2 & $\$ 280-\$ 630$ \\
\hline Range 3 & $\$ 630-\$ 1,050$ \\
\hline Range 4 & $\$ 1,050-\$ 1,475$ \\
\hline Range 5 & $\$ 1,475-\$ 2,105$ \\
\hline Range 6 & $\$ 2,105-\$ 2,895$ \\
\hline Range 7 & $\$ 2,895-\$ 4,210$ \\
\hline Range 8 & $>\$ 4,210$ \\
\hline
\end{tabular}

Source: Own elaboration based on Mobility Survey 2011 
Table 2. Main household's characteristics by income level

\begin{tabular}{|l|c|c|c|c|}
\hline \multicolumn{1}{|c|}{ Income range $\rightarrow$} & $\mathbf{1}$ & $\mathbf{2}$ & $\mathbf{3 - 4}$ & $\mathbf{5}$ to $\mathbf{8}$ \\
\hline Household $(\mathrm{HH})$ size & 2.93 & 3.33 & 3.40 & 3.13 \\
\hline Workers by HH & 1.2 & 1.5 & 1.7 & 1.7 \\
\hline Students by HH & 0.8 & 1.0 & 0.9 & 0.7 \\
\hline Car-ownership per HH & 0.09 & 0.25 & 0.62 & 1.37 \\
\hline Daily trips per inhabitant & 2.1 & 2.2 & 2.3 & 2.6 \\
\hline Motorized daily trips per inhabitant & 0.8 & 1.0 & 1.4 & 1.9 \\
\hline Daily trips per HH & 6.3 & 7.3 & 7.7 & 8.1 \\
\hline Commuting trips per HH & 0.76 & 1.13 & 1.40 & 1.56 \\
\hline Motorized work-trips per worker & 0.47 & 0.58 & 0.67 & 0.80 \\
\hline Public transport work-trips per worker & 0.37 & 0.43 & 0.43 & 0.29 \\
\hline \% of inhabitants without trips & $19 \%$ & $16 \%$ & $15 \%$ & $13 \%$ \\
\hline Motorized travel time to work & 71.0 & 67.1 & 59.9 & 50.2 \\
\hline Public transport (PT) travel time to work & 77.0 & 72.6 & 68.0 & 62.2 \\
\hline
\end{tabular}

Source: Own elaboration based on Mobility Survey 2011 
Table 3. Average job-accessibility improvements (baseline 2011)

\begin{tabular}{|c|c|c|c|c|c|c|c|}
\hline \multirow[t]{2}{*}{ 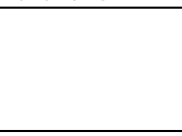 } & \multirow{2}{*}{$\begin{array}{l}\text { Change in } \\
\text { average } \\
\text { travel time }\end{array}$} & \multirow{2}{*}{$\begin{array}{c}\text { Change in fare } \\
\text { (constant } \\
\text { prices) }\end{array}$} & \multicolumn{3}{|c|}{$\begin{array}{c}\text { Change in average transport } \\
\text { costs }\end{array}$} & \multicolumn{2}{|c|}{$\begin{array}{l}\text { Change in average } \\
\text { accessibility }\end{array}$} \\
\hline & & & W/O subs & \multicolumn{2}{|c|}{ W/ subs } & W/O subs & W/ subs \\
\hline $\begin{array}{c}\text { Baseline } \\
2011\end{array}$ & - & - & - & \multicolumn{2}{|c|}{-} & - & - \\
\hline $\begin{array}{c}\mathrm{A} 0 \\
2011 / 2015 \\
\end{array}$ & $+12.8 \%$ & $\begin{array}{l}-1.1 \% \text { bus } \\
-5.5 \% \text { TM }\end{array}$ & $-22.4 \%$ & \multicolumn{2}{|c|}{$-28.0 \%$} & $+6.6 \%$ & $+17.0 \%$ \\
\hline \multirow{12}{*}{$\begin{array}{c}\text { A1 } \\
2011 / 2015\end{array}$} & \multirow{12}{*}{$+12.8 \%$} & \multirow{12}{*}{$\begin{array}{l}-1.1 \% \text { bus } \\
-5.5 \% \mathrm{TM}\end{array}$} & \multirow{12}{*}{$-22.4 \%$} & \multicolumn{2}{|c|}{$\begin{array}{l}\text { Subsidies } \\
\text { variation }\end{array}$} & \multirow{12}{*}{$+6.6 \%$} & - \\
\hline & & & & $-80 \%$ & $-23.5 \%$ & & $+8.5 \%$ \\
\hline & & & & $-60 \%$ & $-24.7 \%$ & & $+10.6 \%$ \\
\hline & & & & $-40 \%$ & $-25.8 \%$ & & $+12.6 \%$ \\
\hline & & & & $-20 \%$ & $-26.9 \%$ & & $+14.8 \%$ \\
\hline & & & & $-10 \%$ & $-27.4 \%$ & & $+15.9 \%$ \\
\hline & & & & $0 \%$ & $-28.0 \%$ & & $+17.0 \%$ \\
\hline & & & & $+10 \%$ & $-28.6 \%$ & & $+18.2 \%$ \\
\hline & & & & $+20 \%$ & $-29.1 \%$ & & $+19.3 \%$ \\
\hline & & & & $+40 \%$ & $-30.2 \%$ & & $+21.7 \%$ \\
\hline & & & & $+60 \%$ & $-31.3 \%$ & & $+24.1 \%$ \\
\hline & & & & $+80 \%$ & $-32.4 \%$ & & $+26.6 \%$ \\
\hline
\end{tabular}

Source: Own elaboration 
Table 4. Public transport affordability indices classified by income groups

\begin{tabular}{|c|c|c|c|c|}
\hline Period & Low-income (R1-2) & Medium-income (R3-4) & High-income (R5 to 8) & Total \\
\hline 2011 & 16.7 & 10.2 & 3.3 & 13.7 \\
\hline 2015 & 9.2 & 5.5 & 2.1 & 7.2 \\
\hline Difference & $-44.6 \%$ & $-46.1 \%$ & $-36.7 \%$ & $-47.3 \%$ \\
\hline
\end{tabular}

All public transport trips were computed.

Source: Own elaboration 
Table 5. Palma ratio

\begin{tabular}{|c|c|c|c|}
\hline \multirow{2}{*}{ Decile } & \multicolumn{3}{|c|}{ Accessibility values } \\
\hline & 2011 & 2015 W/O subs & $2015 \mathrm{~W} / \mathrm{subs}$ \\
\hline Decile $5^{\text {th }}$ (average) & 75,849 & 80,840 & 88,758 \\
\hline Top 10 (richest) & $\begin{array}{c}106,554 \\
140 \% *\end{array}$ & $\begin{array}{l}98,828 \\
122 \% *\end{array}$ & $\begin{array}{c}101,529 \\
114 \% *\end{array}$ \\
\hline Bottom 40 (poorest) & $\begin{array}{c}76,626 \\
95 \% *\end{array}$ & $\begin{array}{l}76,689 \\
113 \% *\end{array}$ & $\begin{array}{l}95,440 \\
108 \% *\end{array}$ \\
\hline Palma ratio & 1.39 & 1.29 & 1.23 \\
\hline
\end{tabular}

${ }^{*}$ Accessibility relative to the average.

Source: Own elaboration 